\title{
Specifications of Cartographic Symbols for Indonesian Tactile Map
}

\author{
Noorhadi Rahardjo, Ika Noor Muslihah M and Candra Sari Djati Kartika \\ Faculty of Geography, Universitas Gadjah Mada, Indonesia
}

Received: 2019-01-03

Accepted: 2019-04-04

Keywords:

visual impairment;

tactile map;

cartographic symbol;

national standard

Corespondent Email:

candrakartika@ugm.ac.id

\begin{abstract}
Visual impairment people require a means of information transfer which different from normal people, it needs to be touched or amplified by audio, including maps that apprise them of the objects and events occurring on Earth. Cartographic Sciences have developed tactile maps that offer touchable symbols for supporting blind and partially sighted people in recognizing the spatial distribution of geographical phenomena and their intercorrelation. Creating an informative tactile map need a specific design of symbol, ancillary information, and map reproduction that meets the need and the capacity of its users. Unfortunately, there has been no international standardization for these map features that could be used as a foundation to build a standardization for our national tactile map. Therefore, this research adopted and modified the designs of tactile symbols published by the National Mapping Council of Australia, the Guidelines for Design of Tactile Graphics by American Printing House, the use of tactile variables by Vasconcellos, the Specifications of Topographic Elements Mapping by Bakosurtanal, and the application of visual variables of Bertin for cartographic mapping. The resultant symbol designs from the modification were applied to develop the tactile maps of Yogyakarta City on swell paper. Then, through interviews with map users (visually impaired people in the city), we evaluated these symbols from two aspects, comprehension of tactile variables and the types of the tactile maps required.
\end{abstract}

(๑) 2019 by the authors. Licensee Indonesian Journal of Geography, Indonesia.

This article is an open access article distributed under the terms and conditions of the Creative Commons

Attribution(CC BY NC) licensehttps://creativecommons.org/licenses/by-nc/4.0

\section{Introduction}

Indonesia as one of the most populated country also has the highest number of visually impairment people (WHO, 2012). Just like normal people, people with visual impairment also need spatial information to understand their environment, but they still have many challenges to obtain this information (Zeng \& Weber, 2011). The most common tool that could be used to help them to understand this information is by using a tactile map. However, tactile map in Indonesia is rare and hard to obtain. In 2007, the Ministry of National Education published a tactile atlas of five continents and Indonesia using thermoform as its media but there is only one atlas for each province which is insufficient for the need of people with visual impairment. One of the major drawbacks in tactile map production in Indonesia is the unavailability of standards or guidelines for designing and producing tactile map.

Some other countries have developed standardization for tactile map producing. National Mapping Council of Australia (1985) published 'A National Specification for Tactual and Low Vision Town Maps' which stated that producing tactile map on swell paper is the most effective technique as it is easier to duplicate and to update the content. The Braille Authority of North America dan the Canadian Braille Authority (2010) published 'Guidelines and Standards for Tactile Graphics' which consist of information about designing and producing tactile graphics and diagram and how to ensure its quality. Nogueira (2009) developed a research about standardization of tactile maps in Brazil which concluded that there are factors that need to be considered to the standardization for the production of tactile maps, which are the cost, the right technology and the specialist to design symbolization and the product should be tested an approved by the visually impaired people. Oh (2018) was conducting a research to design tactile map for blind people in Korea by considering tactile linear generalization and scalable tactile map symbol and layout. The usability test then performed to get feedback from the visually impaired people so that the result could improve Korean tactile mapping guideline.

The production of a tactile map requires careful design. Tactile mapping must fit the purpose. It must take account of the classification, abstraction, symbolization, and standardization processes that are dependent on the readability of map elements in a resolution as wide as a fingertip (Jacobson, 2007). In order to develop national standard for tactile map in Indonesia, this pilot study is carried out to investigate effective design specifications for tactile map symbol and production. 


\section{Methods}

\section{Pre-production}

This pilot study is carried out to design and produce city of Yogyakarta tactile map. Before designing and producing the map production began, we started by conducting a questionnaire-assisted discussion and observation (Gual et al., 2011) with the samples of our target users (visually impaired people) to gain information about what kind of tactile map and spatial information they desire (Jehoel et al., 2005). This discussion and observation also aim to explore the ability of our samples to recognize the tactile variables and their familiarity with tactile graphics. For this research, we are using 60 respondents as our samples which 30 persons are students from 4 th grade until 12th grade and 30 persons are visually impaired workers with age range between $18-41$ years old. The samples also consist of different type of visually impairment, from low vision until total blindness. The result from the discussion shows that the type of tactile map needed using Edman (1992) classification are general reference and orientation tactile map.

\section{Design}

This stage started with the selection of geographical information that were collected from discussion in the previous stage. The selection also based on two references which are Government Regulation No. 10/2000 on the Map Accuracy Level for Regional Spatial Planning (PP No. 10/2000) and the study by Loben et al. (2007). Map scale was determined according to the desired detail and the standard of town mapping, i.e., 1:10,000-1:25,000 for orientation purposes and $>1: 25,000-1: 50,000$ for reference maps.

The design of the tactile symbols should align with the principle of tactile variables. The principles employed in this research were as follows:

1. The simplification or enlargement of the standard symbols on the Indonesian Topographic Map issued by BAKOSURTANAL (2003), used as the main reference for orientation or reference maps with scale $\geq 1: 10,000$;

2. The designs and rules of symbolization published by the National Mapping Council of Australia (1985), used for orientation map with scale $\leq$ 1:10,000;

3. The guidelines for tactile image design released by the American Printing House for the Blind (1997), used for designing layout the map, and
4. Previous studies focusing on the design of tactile map symbols.

There are no conventions for designing tactile maps symbol (Brock et al., 2012), therefore the symbols can be made as simple as possible but still conveniently represent different information that the map users expect. Accordingly, this research designs the tactile map symbols by adopting various considerations, namely, size, distance between label and Braille, height, and distance between symbols and Braille.

1)Size of symbol

The classification is based on the size of the smallest object that the visually impaired people commonly touch or recognize, i.e., one Braille cell or a ball with $1-\mathrm{mm}$ diameter and $0.5-\mathrm{mm}$ height. Therefore, 0.5 $\mathrm{mm}$ was selected as the width of the thinnest single line to accentuate line features, particularly due to the presence of many facilities/objects along local roads in Yogyakarta City. For area symbols that filled with patterns or textures (see Figure 1), there is an exception that the pattern is using a $0.35 \mathrm{~mm}$ thick line. In other certain conditions, the line can be $0.70 \mathrm{~mm}$ thick, and the distance between the lines can be reduced to $3 \mathrm{~mm}$.

2)The distance between labels and Braille cells

- Points, lines, and Braille cells (labels/toponyms) must be separated at least $3 \mathrm{~mm}$

- Knight (2010), an expert in tactile mapping on swell paper, states that $2 \times 2$ Braille dots $(1 \mathrm{~mm})$ is a tolerable distance between symbols as well as an acceptable gap between symbol and Braille cell because visually impaired people are used to detect these dots, which constitute the Braille alphabet.

3)Height of symbol

- Minimum height of each symbol (point, line, area): $0.5 \mathrm{~mm}$.

4)Distance between symbols and Braille cells.

- The initials or labels in Braille that describe certain symbols have to be at least two Braille cells.

- In an analysis that requires a group of maps, the scale and orientation are not necessarily provided on every map sheet when they complicate the data display. Coordinates are presented as simply as possible and not displayed as the main information.

- Title, direction to read tactile map, and legend are placed on the map itself, but they can be placed on the previous sheet if there is not enough space.

- An overlap of $\pm 2 \mathrm{~cm}$ is provided to retain the tactile sensation of fingertips.

Selected geospatial information (borders, roads,
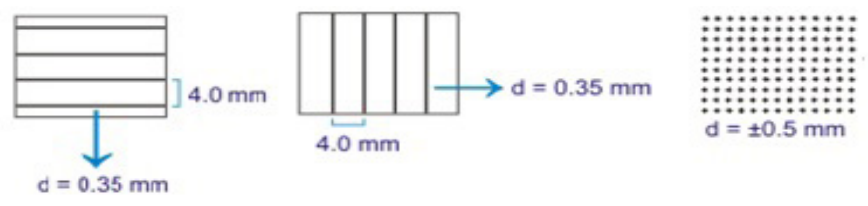

Figure 1. Modification of Area Symbol based on the standard symbols on the Indonesian Topographic Map issued by BAKOSURTANAL (2003) 


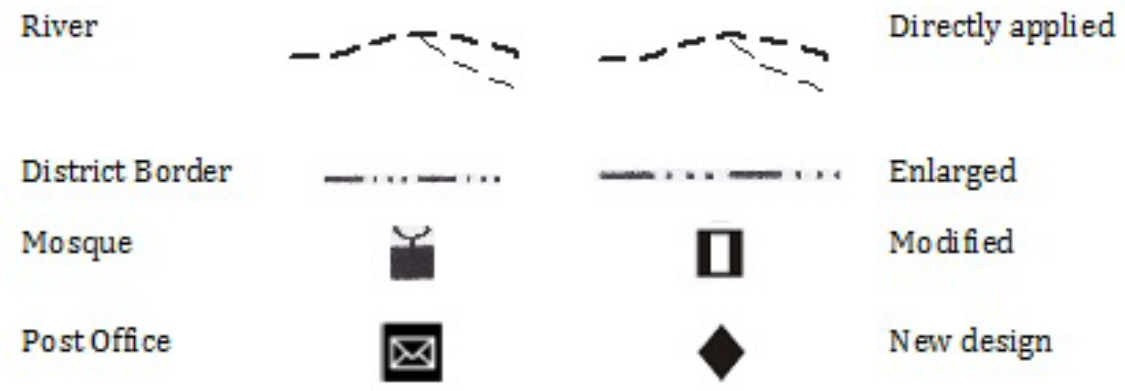

Figure 2. Four treatment to adopt symbol from the existing symbol

\title{
abcdefghij
}

\author{
Swell Braille 24 pt
}
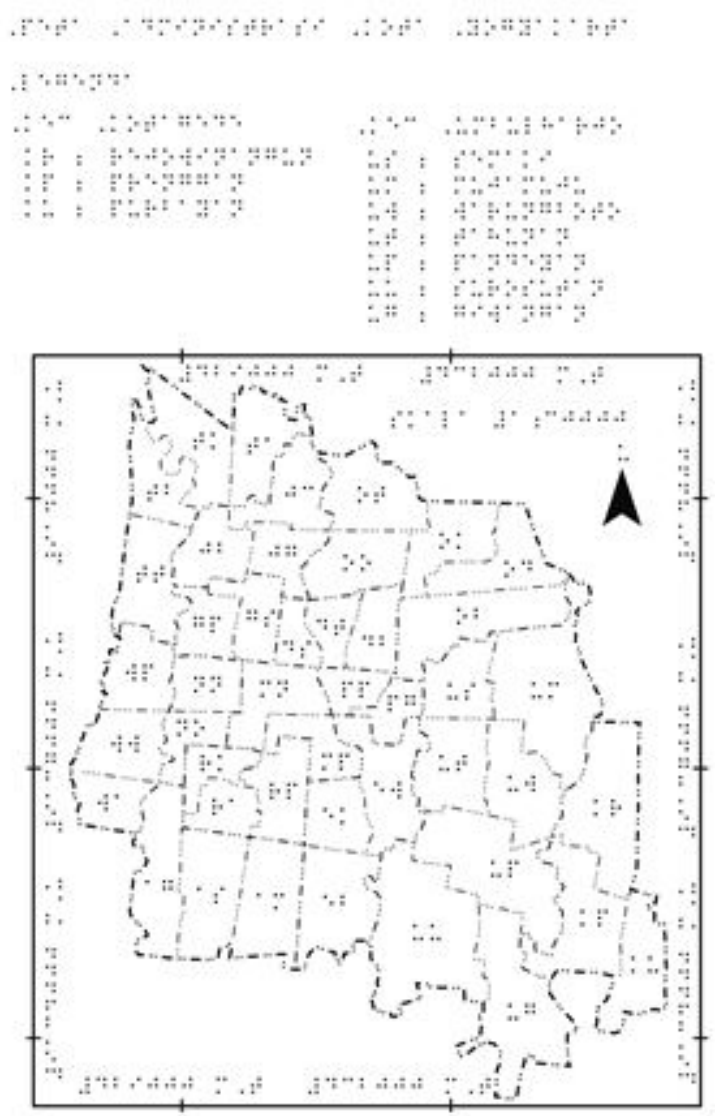

Figure 3. Tactile Map Layout and Labelling

rivers) from Indonesian Topographic Map scale 1:25,000 that covered Yogyakarta City and the Map of Yogyakarta City scale 1:9,000 are processed using ArcGIS 9x software. Generalization process is done to improve the tactile quality of the data, such as selection, simplification especially for line feature, combination for residential area, exaggeration and displacement. Buffering as long as $3 \mathrm{~mm}$ is also done on the line feature (borders, roads, rivers) to give some space between symbols to make it more readable for each symbol.

There are four types of treatment to adopt symbol from existing topographic standard symbol which are directly copied, enlarged symbol to match the minimum size that could be recognize by visually impaired people, modified symbol for the purpose of simplifying and adjusting the size and brand new symbol (Figure 2). Brand new symbol made because the actual symbol was too complex and hard to recognized, therefore a new design was made using simple shape such as rhombus for a certain type of building. All the process of tactual symbol design is fully done using CorelDRAW X4 software. All symbols are depicted using black color to get a tactile impression.

Labeling is also done by using swell braille font type with a size of $24 \mathrm{pt}$. After the entire symbol design process is done, the last step is to create a tactile map layout. Layout was made in portrait format with the upper side of the layout consist of map title and legend, and the lower side of the layout is the main tactile map with orientation and map scale.

\section{Hard-copy Production}

At this stage of production, the tactile map of Yogyakarta City was printed on A3 swell paper (using 
a photocopy process to give a maximum tactile result after heating) and then heated in PIAF Tactile Image Maker machine. In the heating process, we have to be careful so that only the symbols will be developed. After the whole process is finished, the map then organized according to order that was design before to make the City of Yogyakarta Tactile Map.

\section{Result and Discussion}

The Standardization of Tactile Map in Indonesia (Pioneer)

A good map is a correct and effective map. "Correct" means that it represents geographic phenomena according to cartographic rules, while "effective" means that it meets the entire need of map users to the desired extent (not excessive). Therefore communication through a cartographic channel can run optimally. Standardization of tactile maps will ensure effective cartographic communication for visually impaired people and a resource for observation or spatial analysis.

The production of this tactile map resulted in two important outcomes, namely, (1) determining the type of tactile map that the blind and partially sighted people required and (2) specification of tactile map symbols.

\section{The Type of the Desired Tactile Map}

Based on projected use, tactile maps can be divided into several types, namely, mobilization, orientation, and reference. Identification of the types of map that were required by map users was done in pre-production step by surveying two groups of respondents. The survey results proved that these two groups had similar interests in accessing spatial information from tactile map. The interest was to understand regional orientation, as introduced by the relative position of objects in Yogyakarta City, therefore they desire to have a general reference and orientation type of tactile map to produce regularly. The types of the desired tactile map are presented in Figure 4.

\section{Administrative Map of Yogyakarta City}

The Administrative Map of Yogyakarta City is a tactile map designed to display information on administrative divisions, i.e., from municipality down to sub-district level and its border. It functioned as a regional reference sheet, which aimed to provide users with a general description of a region before going further to a more detailed information presented in the Orientation Map of Yogyakarta City. The administrative map has three levels of administrative borders, i.e., municipality/regency (the highest level), district, and sub-district borders (the lowest level).

\section{Orientation Map of Yogyakarta City}

The Orientation Map of Yogyakarta City only displays some selected topographic objects that help map users not only identify an object but also recognize its location relative to another object. This map is designed to improve the spatial comprehension of its users on selected objects and to assist in travel planning. Due to the abundance of objects that attracted the map users, the tactile map had to be produced on a relatively large scale. Consequently, the map needed more media and substrate because the maximal size of swell paper was A3. This tactile map was divided into several sheets.

\section{The Specifications for Tactile Symbols in Town Mapping}

The experience of visually impaired people in exploring their haptics ability shapes the sensitivity level of their tactile sensor, especially the one on their fingertips (Griffin, 2001). The same experience also determines their ability to read and interpret tactile map. Thus, we examined the sensitivity of our respondents to determine which tactile variables could be used for developing our symbols in the tactile map. In this research we used tactile variables proposed by Dinar et al (2005) that consist of profile, orientation, texture, shape, value and size. All respondents stated that all

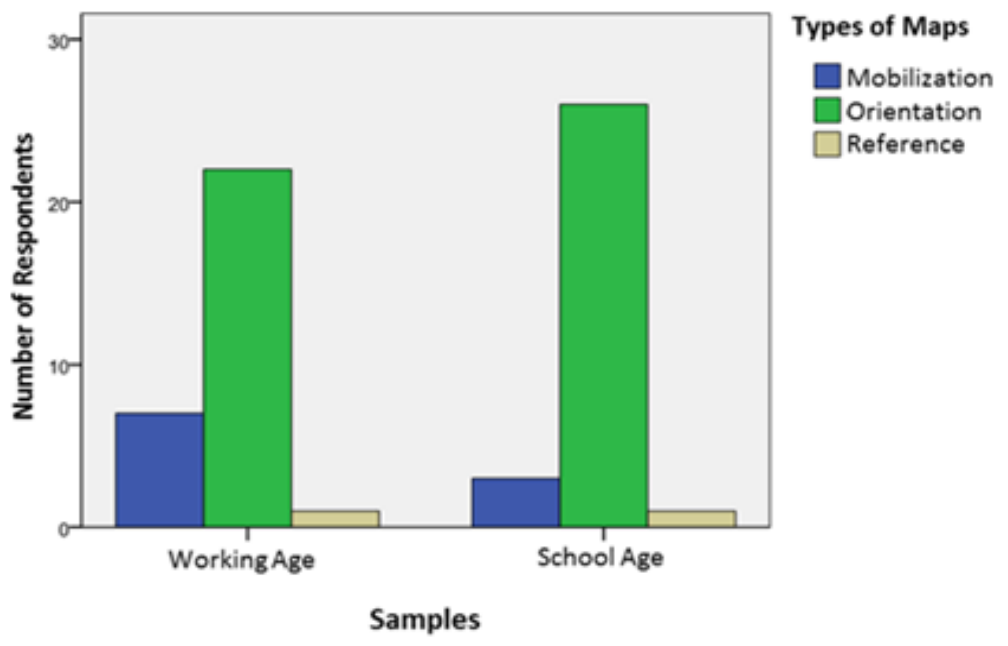

Figure 4. The Types of Tactile Maps Desired by Two Different Age Groups 
Table 1. Percentage of Respondents Comprehension on Tactile Variables

\begin{tabular}{ll}
\hline Tactile Variables & $\%$ of Respondents \\
\hline Profile & $88 \%$ \\
Orientation & $93 \%$ \\
Texture & $98 \%$ \\
Shape & $100 \%$ \\
Value & $90 \%$ \\
Size & $97 \%$ \\
\hline Source: Survey results
\end{tabular}

Table 2. Percentage of Selected Information for Tactile Orientation Map Production

\begin{tabular}{ll}
\hline Mapped Objects & Percentage \\
\hline $\begin{array}{l}\text { Buildings and their } \\
\text { surrounding facilities }\end{array}$ & 100 \\
Transportation & 100 \\
Relief and control & 3.33 \\
points & \\
Open space & 21.67 \\
Administrative borders & 30 \\
Water bodies & 43.33 \\
Labels/Toponyms & 100 \\
\hline Source: Survey results &
\end{tabular}

of the tactile variables introduced in the Orientation Map of Yogyakarta City were understandable. Based on central tendency analysis, shape, texture, and size were highly recognizable, while orientation, value, and profile were rather difficult to identify. As a result, (1) all of the tactile variables can be used in the development of tactile symbols and (2) size, texture, and shape are the tactile variables that have the highest potential to structure cartographic symbols in tactile mapping therefore in designing and modifying new symbol for the tactile map we mostly used shape, size and texture as our consideration factors. Table 1 presents the proportion of respondents who understood symbols based on each of the tactile variables.

As mentioned previously, visually impaired people have a limitation in recognizing all objects on the Earth's surface. Therefore, they have a certain interest in many elements presented in a tactile map. All respondents requested three object classes (see Table 2): (a) buildings and their surrounding facilities, (b) transportation, and (c) toponyms or geographic names. These became the primary objects depicted on the tactile map.

The percentage of object selection used as a basic consideration to select topographical information to be represented on map as an effort to accommodate the need of visually impaired people. But not all the building, facilities or roads could be depicted on tactile map, therefore there is another selection to choose important sites such as main roads, government offices, schools as these sites mostly used by all respondents.

As symbol for tactile map has different requirement in size than topographical map, generalization process could not be avoided. Most of the generalization process are exaggeration, simplification and displacement. Exaggeration mostly happened for roads, while simplification happened for point symbol such as buildings, while displacement happened because some objects have to shifted because the roads exaggeration.

Swell paper is used as our media to print the map, as swell paper could be produced easily in Indonesia so that it will reduce the cost in making the map and it easier to find so the production could be done regularly but there is a limitation due to the size of the paper that could only be printed in A3 size that could be a bit bigger to bring it everywhere so the visually impaired people mostly used it at home before they go to the place they want to get a basic orientation about the environment. As the map is a product with unified information needed by the visual impairment people for the sake of spatial orientation in the region, careful consideration of the map structure is needed. The map consecutively composed of the title sheet and supporting information of the map, next is the legend sheet of the map symbol in general, administrative map of Yogyakarta scale 1: 30.000 which is equipped with index, tactile map of Yogyakarta City sheet al scale 1: 10.000, then followed by sheets a1, b1, a2, b2, a3, and b3. The index is used to determine the map sheet, as the Yogyakarta City Map which produced for the orientation purposes has scale of 1: 10,000 and is composed on six separate map sheets. The legend sheet of the general map symbol is placed before the map because most of users request it as they want to study the map symbol first to be familiar with it so that it will be easier for them to read the map.

Evaluation of the final product was done to some visually impaired people in Jakarta. This evaluation was conducted to derive information about the usability of the tactile map to the people who do not have any local knowledge about the area on the map. The result of this evaluation shows that design of the tactile map is quite good for a starter, yet there are many things that need to be improved such as some different symbols give the same perception because the shape is quite similar such as symbol for different worship place, that uses orientation to differentiate the symbol, feels similar so further modification need to be done. Another finding is that road network thematic map should also produce separately without adding sites or POI information to give better understanding about general condition of the network. Discussion with Ormelling, other cartography expert, added new insight for the symbol design. Some symbol with too complex shape such as combination between circle and trapezoid or symbol with many angles will be harder to read and there is a sheet ( 22 sheet) that contains too much information that it is need a longer time to understand the information on the map. According to these results and literature 


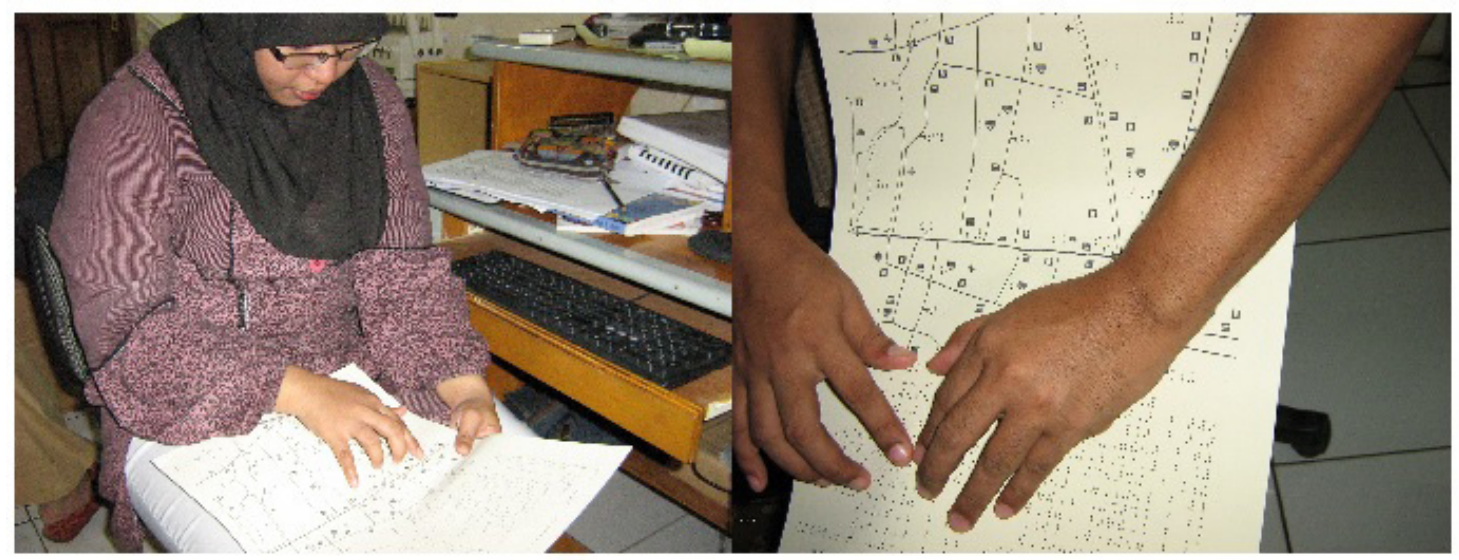

Figure 5. Evaluation of the final product

reviewed above, tactile map symbols can be developed further so that many information could be depicted clearly on map and the research could be conducted in more complex area such as our capital city to compare the result.

These designs could be used proposed as a basis for further research to build symbol standardization of tactile map in Indonesia. A wider range of respondents could be involved to gain more information about the usability of the symbol, to make sure that the standard could be used nation wide. Cooperation with institutions or organization that support the visual impaired people is needed to assist for future research as they have a better understanding and more knowledge about the users need and to help to raise funding to produce the tactile map to make it more accessible for the people that need it and wider audience. A research about other technique to visualize the product could also be done, such as using 3D visualization (Gual-Orti et al., 2013) or interactive visualization, to find a better way to visualize and to produce the product so that the users could get understand the information from the product easily.

\section{Conclusion}

Designing and producing tactile map requires careful consideration and proper development. In this research, the tactile map of Yogyakarta City was created as a general reference and orientation map to introduce regional orientation and suit the need of blind and partially sighted people in the city. A specification of symbol for tactile map was develop using combination of four reference to build a standardization of tactile map design and production in Indonesia. The production of this tactile maps included many generalization processes, namely, simplification, enlargement, displacement, and selection, which led to inaccurate absolute position on the map. Therefore, the map focused on the relative position of an object to its surroundings. Some standard symbol from the topographical map symbol was keep, some was modified and enlarged, but some need to be newly drawn. As this map was made on a large scale because its users need many topographic elements that depicted at a scale least recognizable by fingertips, the limitation dimensions of the media we used (swell paper) forced us to printing it in mosaic (i.e., the area covered in the map was divided into several sheets). Consequently, the users perceived the printed tactile map as less practical as the printed map has quite larger dimension than average book (A3 size) and consist of several sheets. The specification that we proposed in this research could be used as a base to more research to develop standardization of tactile map symbol in Indonesia as our result is still far from perfection. Cooperation with organization that concern with visually impaired people and government need to be build so that the research about designing and producing tactile map could be developed continuously due to the potential use value to broad the visually impair people knowledge about their surroundings through these maps.

\section{Acknowledgement}

We would like to give our gratitude to WCRU (World Class Research University) Team for helping us in the making of the standard specification for symbolization of national tactile map.

\section{References}

American Printing House for the Blind (APH). (1997). Guidelines for Design of Tactile Graphics. Retrieved from https://www.aph.org/research/guides/

Bakosurtanal. (2003). Indonesian Topographic Map Symbol Standard. Indonesia.

Brock, A., Truillet, P., Oriola, B., Picard, D., \& Jouffrais, C. (2012). Design and User Satisfaction of Interactive Maps for Visually Impaired People. In Miesenberger, K.; Karshmer, A.; Penaz, P.; Zagler, W. (eds.) ICCHP 2012. Lecture Notes in Computer Science (Vol 7383, 544-551). Springer, Heidelberg.

Dinar, S., Rowell, J., \& McCullum, D. (2005). The Uniqueness of Symbol Profile as a Design Variable in Tactile Cartography. Paper presented at The 22nd International Cartographic Conference, Coruna, Spain.

Edman, Polly K. (1992). Tactile Graphic. New York: American Foundation for the Blind.

Griffin, A.L. (2001). Feeling It Out: The Use of Haptic Visualization for Exploratory Geographic Analysis. Cartographic Perspectives, 39, 12-29. 
Gual, J., Puyuelo, M., Lloveras, J. (2011). Universal Design and Visual Impairment: Tactile Products for Heritage Access. Proceedings of the International Conference of Engineering Design (ICED11) (pp. 155-164), 15-18 August, Techincal University of Denmark.

Gual-Ortí, J., Puyuelo-Cazorla, M., \& Lloveras-Macia, J. (2013). Improving Tactile Map Usability through 3D Printing Techniques: An Experiment with New Tactile Symbols. The Cartographic Journal, 52(1), 51-57. https:// doi.org/10.1179/1743277413y.0000000046

Jacobson, R.D. (2007). The Future of Tactile Cartography: From Static Raised Lines to Multimodal Dynamic Portable Computer Interfaces. Abstracts of Papers XXIII International Cartographic Conference. Moscow, Rusia, 358.

Jehoel, S., Ungar, S., McCallum, D., \& Rowell. (2005). An Evaluation of Substrates for Tactile Maps and Diagrams: Scanning Speed and User Preferences. Journal of Visual Impairment and Blindness, 99, 85-95.

Loben, A., Fickas, S., Lawrence, M., Yao, X. (2007). Tactile Mapping Software for Blind and Low Vision Science Education. Paper presented at: the NSF-HRD Joint
Annual Meting. Washington DC.

National Mapping Council of Australia. (1985). A National Specification for Tactile and Low Vision Town Maps. Canberra, Australia.

Nogueira, R.E. (2009). Standardization of Tactile Maps in Brazil. Proceedings of the XXIV International Cartographic Conference. 15-21 November. Santiago, Chile. https://icaci.org/files/documents/ICC_ proceedings/ICC2009/html/refer/8_1.pdf

Oh, ChungWeon. (2018). Designing of Tactile Map for Blind People in Korea. International Journal of Civil Engineering and Technology (IJCIET), 9(11). 22452251. ISSN 0976-6308.

The Braille Authority of North America and the Canadian Braille Authority. (2010). Guidelines and Standards for Tactile Graphics. Retrieved from http://brailleauthority. org/tg/web-manual/

Zeng, L., \& Weber, G. (2011). Accessible Maps for the Visually Impaired. Proceedings of the Workshop on Accessible Design in the Digital World 2011 (pp. 54-60). 5 September. Lisbon, Portugal. 